\title{
OS JAGUNÇOS ou OS TORTUOSOS CAMINHOS DA NACIONALIDADE
}

\author{
Marilene Weinhardt*
}

Eles receberam o esplêndido e misterioso batismo do sangue e, cintos dessa púrpura, abriram as portas da nacionalidade brasileira para seus irmāos sertanejos.

Afonso Arinos, 1897.

Não sei de alguém da época que tenha sentido, compreendido e proclamado tāo lucidamente como ele, o caráter daquele momento histórico. Canudos é um dos momentos decisivos de nossa história.

Alceu Amoroso Lima, 1922.

A leitura, portanto, ficcionaliza a História.

Benedito Nunes, 1988.

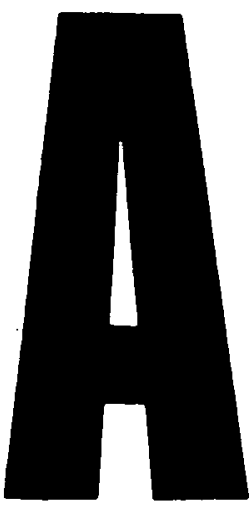

tradição literária em língua portuguesa volta-se para a história com considerável freqüência. $O$ passado se fez presente com intensidade durante o Romantismo. Exemplares neste sentido sāo os romances históricos de Herculano e os de Alencar, para citar uma vertente nacional. Recentemente, nova tentativa de "romance de fundação" verificou-se na literatura brasileira, enquanto realização ainda aquém do projeto romântico. ${ }^{1}$ Nestes casos optou-se pelo passado distante. $O$ presente, nas suas repercussōes sociais e políticas, ocupou a atenção de larga fatia da produção brasileira dos anos de 1960 e 1970, passando a literatura a exercer as funçōes de

* Universidade Federal do Paraná

${ }^{1}$ Pensamos sobretudo no romance de João Ubaldo Ribeiro, Viva o Povo Brasileiro. 
outros meios reprimidos, nem sempre mantendo o nível estético, como demonstrou a crítica já nos primeiros anos da década de 1980.2 Embora neste trabalho o propósito nāo seja o de rastrear um veio que leve à sistematizaçāo das relaçōes entre história e literatura, nāo tendo os exemplos lembrados quaisquer pretensōes de caráter exaustivo, vale notar que os dois momentos indicados, aos quais seguramente se pode agregar o modernismo, têm em comum a questāo emergente do nacionalismo, que aflora em circunstâncias sóciohistóricas diferentes, em manifestaçōes significativamente diversas. Num reducionismo grosseiro, seguindo a determinante cronológica, pode-se explicar a presença do traço recorrente pela urgência de construir a naçāo, pela busca de identidade estética e, mais recentemente pela necessidade de encontrar e marcar o espaço ideológico.

Esse nacionalismo sempre latente na literatura brasileira, pronto a emergir de modo mais premente nos períodos ideologicamente críticos, registra um de seus picos no momento histórico da passagem do Império para a República, manifestado de forma altamente agônica, na sua variante construção da nacionalidade, cuja expressão por excelência é Policarpo Quaresma, a personagem de Lima Barreto. Nesta linha de reflexāo crítica inscreve-se o relato de um episódio da história do Brasil, ocorrido em 1896-97, que certamente não se teria popularizado tanto se nāo tivesse merecido a atenção de um engenheiro-jornalista que foi, antes de tudo, um escritor. Sem Euclides da Cunha, sem o seu livro Os Sertöes, publicado em 1902, os acontecimentos de Canudos não teriam a mesma atenção que têm merecido. Seja porque representou o mea culpa das elites, como entende Thomas SKIDMORE, ${ }^{3}$ seja pelas qualidades estilísticas da narrativa, como querem críticos de tendências mais estetizantes, o fato é que o episódio de Canudos encontrou sua expressāo ideal na pena de Euclides.

O exame dos jornais da época ${ }^{4}$ é termômetro seguro para aferir o alto grau de interesse que os eventos ocorridos no sertão da Bahia despertavam no litoral civilizado. Euclides não foi o único a perceber o potencial dramático do confronto entre os seguidores de Antônio Conselheiro e o Exército da República. Obscura "novela sertaneja", conforme classificação registrada no subtítulo, de autor bastante conhecido no ambiente intelectual da época, mas publicada sob pseudônimo, focaliza os mesmos acontecimentos. Os Jagunços, ${ }^{5}$ de

${ }^{2}$ SUSSEKIND, F., 1985. Particulamente Cap. II, p.42-67.

${ }^{3}$ SKIDMORE, T., 1989, p. 126.

4 A propósito vf. GALVĀO, W.N., 1974.

5 ARINOS, A., 1969, p.121-383. As citaçōes extraídas do romance traräo a indicação de páginas no próprio corpo do texto, referindo-se sempre à esta ed ição. 
Afonso ARINOS, aparece em folhetins diários do Comércio de São Paulo, já em outubro/novembro de 1897, saindo em volume no ano seguinte, publicado pelo próprio jornal, constando Antônio Rocha Ribeiro como editor, mantendo-se o pseudônimo Olívio de Barros. ${ }^{6}$ A tiragem foi limitada a cem exemplares e a reedição só ocorreu na Obra Completa, em 1969, cinqüenta e três anos depois da morte do autor. Daí Afonso ARINOS de Melo Franco (sobrinho do autor em questão) afirmar no prefácio intitulado "O Sertanejo Afonso Arinos": "É, assim, um quase inédito, o livro que aparece neste volume"?

Estudando paralelamente Euclides da Cunha e Afonso Arinos, em ensaio intitulado "De Sertōes e Jagunços", 8 Walnice Nogueira GALVÃO mostrou pontos de aproximação (são contemporâneos, ambos moram em Sāo Paulo) e de distanciamento (pertencem a extração social diversa, freqüentam círculos intelectuais diferenciados, têm opçōes políticas antagônicas), detendo-se no confronto entre as obras, para concluir, sobretudo com base na recorrência de imagens, ser provável que Euclides tenha lido e mesmo utilizado o romance de Arinos como fonte ou ambos "se serviram de uma outra fonte que deixou nas obras de ambos uma mesma e inconfundível marca." $9 \mathrm{O}$ destino de $O s$ Jagunços dificilmente fugirá da comparação com $O s$ Sertôes. Este é o caminho que a crítica tem seguido a respeito de Afonso Arinos, quando nāo se detém na discussāo da autenticidade ou não do regionalismo de seus contos, mas permanece em generalidades, com intenções e propostas diferentes das que orientam o citado trabalho de Walnice. Sirva de exemplo Wilson MARTINS que, em crítica de jornal publicada na ocasião do aparecimento da Obra Completa e reiterada posteriormente, classificando o romance como "a sua (de Afonso Arinos) obra menos importante", justifica a aproximação para mostrar "o extraordinário sentido que adquire como contraste para a obra de Euclides da CUNHA", 10 ou seja, só serve para reforçar o valor do último. Mas quando o caminho escolhido é o de considerar a obra em sua individualidade o resultado pode ser uma leitura ainda mais equivocada, julgando que o uso de pseudónimo e a localização da ação em Belo Monte constituem "ao que parece medida de cautela política numa época ainda carregada de paixöes políticas","1 ignorando o código literário e a realidade

6LIMA, Alceu Amoroso, 1966, p.567, p.577-9.

7 ARINOS, A., 1968, p.27.

${ }^{8}$ GALVĀO, W.N., 1976, p.67-87

${ }^{9}$ Ibidem, p. 78.

10MARTINS, W., 1977-78, p.44

${ }^{11}$ LOUSADA, W. Citado por COUTINHO, A., 1986, p. 282. 
histórica, como se o uso de pseudônimo não estivesse integrado aos hábitos da época, como se não fosse Afonso Arinos monarquista confesso, colaborador e diretor do jomal com pretensöes de promover a restauração do trono, e como se Belo Monte fosse um nome ficcional e não aquele pelo qual os sertanejos identificavam a povoaçāo fundada pelo Conselheiro, ponto de vista com o qual o narrador busca identificar-se, embora o texto registre também a denominaçāo Canudos. Outra saída é centrar os comentários no enredo e caracterização de tipos da primeira parte do romance, usando como argumento a informação de Tristāo de Ataíde, segundo o qual Afonso Arinos pretendia refundir o livro, dividindo-o em dois e fazendo do episódio "A morte de Conceição, que encerra muita coisa interessante, um livro à parte", ${ }^{12}$ nāo comprometido com os "fatos históricos". A abordagem como se tal livro tivesse se concretizado permite mostrar que o autor caracteriza bem ambientação interiorana e personagens sertanejos, juízo muito mais defensável pela análise dos contos de Pelo Sertão, estratégia empregada por Alceu Amoroso LIMA em texto datado de $1922,{ }^{13}$ exemplarmente expressionista, mas que parece ser ainda o texto crítico mais preciso sobre a obra de Afonso ARINOS.

Para situar Os Jagunços estética e historicamente, cumpre observar detalhes do trato da matéria ficcional e suas relaçöes com as peculiaridades do momento sociopolítico vivido pela nascente República brasileira. Note-se que sua publicação se dá praticamente "no calor da hora", para emprestar a sugestiva expressão de Walnice Nogueira GALVĀO.

Em longo artigo publicado pelo Comércio de São Paulo a 9 de outubro de 1897, portanto no dia seguinte ao anúncio da rendição, sob o título "Campanha de Canudos" (O Epilogo da Guerra), Afonso ARINOS demonstra extraordinária lucidez e recusa uma interpretaçāo imediata ao afirmar:

essa luta deveria merecer a atenção dos publicistas, para ser estudada, nāo simplesmente na trágica irrupção e no desen volvimento, mas em suas origens profundas, como um fenômeno social importantíssimo para a investigaçāo psicológica e o conbecimento do caráter brasileiro. 14

\footnotetext{
12 LINHARES, T., 1987, p. 100.

13 LIMA, A.A., 1966.

14 ARINOS, A., 1969, p.644.
} 
É a busca dessas "origens profundas" que determinam a estrutura externa do romance. Dividido em duas partes, a primeira com quatro capítulos, ocupando cerca de um terço do total de páginas, decididamente fictícia, é toda dedicada a mostrar como é a vida do sertanejo: meios de sobrevivência, estrutura social, festejos, princípios morais, etc. É na segunda parte, composta de cinco capítulos, que se situa a ação histórica. O fio narrativo é sustentado por uma personagem sobre a qual não se encontra registro histórico, Luís $\mathrm{Pa}$ chola, no princípio camarada de um tropeiro e por quem desperta o coraçāo da bela e faceira mulata Conceiçāo, protegida da família do fazendeiro que realiza a festa do Espírito Santo. O amor é fatal para ela, morta pelo punhal do apaixonado, vaqueiro Gabriel (neste está centrado o terceiro capítulo, "O Vaqueiro"), quando tenta assassinar o involuntário rival. Por sua vez, o desastrado ciumento suicida-se espetacularmente. Na tentativa de criar uma versão caipira do Otelo, o narrador procura dar-lhe feições trágicas, mas o efeito é antes cômico. O camarada segue a vida errante de sua profissāo, a partir daí sempre acompanhado pela lembrança daquela que sacrificou a vida por ele. Mas o acaso propicia o reencontro com "o missionário" (título do segundo capítulo), que já aparecera nas cenas iniciais da narrativa, num ato de "encomendação" (que dá título ao primeiro capítulo), e pregando durante a malograda festa. "A profecia" (quarto capítulo) que fizera então, antevendo a perda do gado do tropeiro na travessia do rio, confirma-se, o que lhe vale o ódio do patrăo e a devoção do camarada, que logo passa a compor a caravana dos peregrinos que o seguem.

As falhas de estruturação narrativa, sobretudo no trato do tempo ficcional (rupturas inoportunas e inábeis da linearidade, inépcia na representação da passagem do tempo) e no alongamento excessivo da descrição de cenas pelos seus aspectos típicos, buscam compensação na vivência que o autor demonstra do interior brasileiro, seja mineiro, goiano ou baiano. O conhecedor do sertāo distingue insistentemente o camarada do vaqueiro, o fazendeiro do tropeiro, distinções significativas num espaço social estratificado, cuja moral repousa sobre valores indiscutíveis e imutáveis, mas também não resiste à oportunidade de descrever minuciosamente a festa do Divino, o Congado ou a "sala dos arreios", detalhes sem qualquer funcionalidade, em prejuízo da tensão ficcional. O que ocorre aí de singular é o fato de a narrativa estar centrada nas camadas inferiores, deixando os conflitos da casa-grande e atentando para o pátio, os currais, as casas dos vaqueiros e os dramas que aí se desenrolam. É uma tentativa de deixar o alpendre, embora o efeito ainda seja o de um olhar e ouvidos curiosos, não integrados ao ambiente e que não resistem aos 
aspectos pitorescos. O intelectual com pretensōes de porta-voz do povo, escrevendo para o deleite de cidadāos burgueses com vagas aspiraçōes de revoluçāo proletária, evidentemente desde que todos tenham suas prerrogativas asseguradas, tem larga tradição na cultura brasileira. Afinal até o gênero romance, produto importado, é uma invenção para consumo da classe média. ${ }^{15}$

Na segunda parte, iniciada por período com sabor de conto de fadas (Passaram-se anos, p.202), o missionário já está transformado em Conselheiro, estabelecido com seu povo em Belo Monte. Luís Pachola também lá está, cuidando da velhice da mãe de Conceição, tia Joana, que por sua vez se decidira a seguir o missionário na construçāo da "nova Siāo" anunciada nas premoniçóes da Parte I. O relato passa a seguir o tempo histórico com rigor cronológico de documento, retratando episódios conhecidos, como se pode depreender já pelos títulos dos capítulos: primeiro - A Cidade Santa; segundo A Expediçāo; terceiro - Os Fanáticos; quarto - A Guerra; quinto Último Reduto. A diferença da narrativa ficcional com o relato jornalístico ou com a crônica histórica está nos detalhes que o narrador de ficção pode permitir-se: minúcias sobre determinado acontecimento, pequenas alteraçōes no curso dos fatos, preenchimento dos vácuos da história oficial, descrição de intençōes e emoçōes das personagens, juízos, liberdade na opção de foco narrativo. ${ }^{16}$ Nesta parte o narrador procura manter-se predominantemente junto aos jagunços, mudança dificilmente perceptível na leitura enquanto folhetim. Mas muitas vezes a tentação de uma análise de cunho sociopolítico parece irresistível, em intervençōes totalmente inoportunas. Um exemplo ocorre em pleno relato do combate em que sai mortalmente ferido o comandante Moreira César, relato interrompido por quatro extensos períodos sobre a "psicologia das massas" (p.275). Essa espécie de congelamento da cena distende a tensão e esvazia a emoção. A pretendida identificação narrador igual jagunço permanece num nível mais superficial, no plano da ação, em atitudes como só posteriormente dar os nomes dos comandantes, e só incidentalmente, uma vez que os jagunços não os conheciam de antemão e não deviam dispensar-lhes maior atenção. A luta é uma questão de sobrevivência, sempre limitando-se a manter a posição de defesa. Não há referências mais precisas às atrocidades cometidas de parte a parte. Inclusive depois dos primeiros confrontos os jagunços enterram os cadáveres indistintamente e em certa passagem Luís Pachola recrimina severamente um companheiro que ameaça usar o facāo num

15 WATT, 1., 1990, p.34-54.

${ }^{16}$ A propósito ler WHITE, 11,1985 
"homem caído". O antigo camarada dá-lhe de beber e se comove com a repetição da morte em seus braços, evocando o passamento de Conceiçāo (p.276). O narrador utiliza o artifício para, personificado em Pachola, frisar o caráter humanitário do sertanejo, com passado e com sentimentos, quando a maioria dos artigos da imprensa contemporânea retratava-o semelhante ao animal irracional. Os aspectos domésticos e pacatos do cotidiano na cidade sāo reforçados pelos encaixes de episódios amorosos e cenas familiares. Nestas as mulheres são o centro das atenções e aí o burguês com fumos aristocráticos não disfarça o patriarcalismo de sua casta, somando-o à visão determinista da época. A obrigação dos homens é proteger tais seres fracos e incapazes, embora as mulheres sejam vaidosas, impressionáveis e curiosas. Tais características nāo sāo atribuídas a esta ou aquela personagem, mas descritas como prerrogativas do sexo. Embora ideológica e esteticamente o livro esteja mais próximo de códigos vigentes em décadas anteriores, encontram-se outros ecos de cientificismo, como atribuir a uma personagem a "cor arroxeada que indica as terras de muita seiva." (p.257).

É nas personagens fictícias que o narrador se sente em liberdade para idealizar e construir alegorias à vontade, enquanto as personagens históricas como Pajeú, Vila Nova, Macambira, Beatinho, João Grande, Taramela e José Venâncio estāo presos à contingência humana. ${ }^{17}$ Sem dimensionamento épico, a recriação pouco vai além de introduzi-los como personagens secundárias nas ações fictícias e dar-lhes papel decisivo na reconstrução das açōes espetaculares descritas também em Os Sertóes e que naturalmente eram de dominio público, divulgadas pelo noticiário da imprensa, tais como as tentativas de tomada de canhōes por João Grande e pelos Macambira. Sobre o dúbio estratagema de busca de reforços ou de fuga elaborado por Vila Nova, o narrador se abstém de dar uma resposta conclusiva. Mas o fictício Pachola é caracterizado como protótipo ainda romântico do sertanejo simples, bom, honrado, crente, fiel, irmanado com a natureza. Ele só tem um momento de dúvida e questionamento quando se vê transformado em "matador de gente" (p.240), contrariando os conselhos do missionário e os preceitos da mãe. Mas a Natureza, mãe suprema, é quem imediatamente oferece a resposta. $O$ trecho é longo mas significativo para se examinar o nível de explicitaçăo do narrador:

A colméia fora tomada de assalto por um enxame de

17 A experiência de transformar personagens históricas em alegorias nāo produziu resultados satisfatórios em $A$ Guerra do Fön do Mundo, apesar das inegáveis qualidades narrativas de Vargas Llosa. 
marimbondos, desses que vivem de banditismo. Travara-se ali verdadeira batalha e as abelhas jataís. täo trabalhadeiras e tão mansas. juncavam o chấo. A casa lhes fora tomada depois de heróica defesa, em que as pequeninas perderam a vida. Agora, lá dentro, os vencedores, já bêbados de mel, zumbiam refestelados nos favos. (...)

Aqueles bichinhos que ali estavam mortos eram cem vezes mais numerosos que Luís e seus companheiros; eles tinham pelejado juntos, reunidos para a defesa de sua cidade e de seus filhos. Entretanto, lá estavam os outros de posse da casa, festejando o triunfo.

(...)

E, de repente, começou a pensar na colmeia de Belo Monte, investida por milhares de soldados, nas casas varejadas, nas ruas juncadas de mortos (. . . ) (p 242-3). estabelecer.

Ao leitor não resta qualquer elaboração, qualquer associação a

É pela comunhão com a natureza, promovida inclusive a combatente, que se explica a incrivel resistência: "Parecia que a natureza toda que alimentara aqueles pelejadores, a terra que dera a vida a tais guerreiros consubstanciara seu espírito e erguia-se como um inesperado combatente." (p.374).

As açōes dos jagunços alcançam sucesso muitas vezes, apesar do anacronismo de suas armas, pela capacidade mimética em relaçāo ao espaço que habitam. As comparaçôes do tipo "como uma onça, como uma cobra, como um jaguar. . ." ocorrem no texto à exaustão. Os habitantes de Belo Monte sāo verdadeiros pactários, tendo o missionário celebrado o pacto:

Foi essa natureza bravia que o missionário chamou a seu serviço: (...)

Mas a natureza circundante, embora acudisse à palavra do missionário, não se lhe submeteu sem um contrato: os homens que ali morassem teriam de irmanar-se com a regiāo. E eles se irmanaram. A eles, só a eles, as catingas dariam acesso franco: para eles, a terra seca exsudaria mananciais pelos buracos das cacimbas; para eles, os espinheiros encolheriam as garras e as escarpas baixariam o dorso. Na terra das catingas medrou o jagunço. (p.204)

Daí vem o caráter encantatório, às vezes escatológico, que a 
luta tomava aos olhos dos soldados, para quem os sertanejos figuravam ressurrectos ou as carabinas pareciam atirar por conta própria. Até os animais, sobretudo as vacas contribuem para criar o clima que N. FREYE denomina "solene simpatia", que "numa obra de ficção mais realística, indica que o autor está tentando dar a seu herói algumas das implicações do modo mítico." 18 Mesmo as macabras cenas de mumificação descritas por Euclides da CUNHA ${ }^{19}$ transformam-se em ato de "ternura de māe amorossa pelos cadáveres dos pelejadores" (p.348), ignorando-se que a mesma ação ocorria nas hostes adversárias.

Honório Tico-Tico é modelo de personagem identificada à natureza até no apelido. Dele se diz ter corpo fechado, fenômeno não desmentido pelo narrador, antes confirmado, uma vez que Honório é um dos sobreviventes, apesar dos perigos a que se expóe nos artifícios que inventa, sempre em consonância com a natureza, como disfarçar-se de árvore para buscar água. A ele é atribuído o papel do atirador solitário registrado também por Euclides da CUNHA. ${ }^{20}$ Mas sua atuaçāo de bufo de plantāo é de um histrionismo extemporâneo e deslocado, embora se considerado isoladamente tenha certa expressão, criação típica do Afonso Arinos admirador e fixador de tipos sertanejos.

A ação militar também é representada como digna de admiraçāo. Valente, bravo, fero são os adjetivos que qualificam os soldados. Em nenhuma passagem encontra-se o tom de crítica irônica que permeia $O s$ Sertóes. Inclusive os momentos de maior fragilidade merecem explicaçōes de cunho sociológico ou psicológico. O Exército não é questionado. O papel de vilāo da história (e da História) é reservado exclusivamente ao governo. A culpa do mal-entendido que gera o caráter político que o movimento tomou, cabe à incompreensāo e insensibilidade do "Governo da República, desde o Sr. Vitorino até o Sr. Prudente de Moraes e Luís Viana" 21 como Afonso ARINOS já denunciava no artigo de 9 de outubro. Ele não demonstra preocupação com as filigranas da disputa entre facções civis, jacobinas ou militaristas, figurando o poder "como se monolítico fosse o grupo dirigente," 22 para empregar a expressão de Raimundo Faoro a propósito da denúncia monarquista. O narrador deixa sua posição de empatia com os sertanejos para registrar a comoção do comandante com o "gemido terrível" (p.333) que chega ao acampamento

18 FR YE, N., 1973,p.42.

${ }^{19}$ CUNHA, E. da., 1985, p. 368,396

20 Ibidem, , p.450.

${ }^{21}$ ARINOS, A., 1969, p.645.

${ }^{22}$ FAORO, R.. 1987, p.552 
quando explode uma granada na igreja e a admiração dos soldados, manifestada em mais de uma ocasiāo, diante da coragem dos jagunços. Já no primeiro confronto a situaçāo é retratada de modo que no diálogo fique claro que os adversários sāo da mesma cepa, animados por idênticos ideais. E o autoproclamado porta-voz explica:

Dos graúdos das terras grandes, do Governo que eles consideravam a personificação da força e da riqueza, não conheciam o mínimo benefício.

As únicas vezes que entraram em contato com o Governo, foi por meio das balas e das baionetas da polícia. Desamparados nos seus sertōes, eles sentiam, de vez em quando, a açāo do Governo à passagem dos recruta dores, ou dos aliciadores de tropas. Nas suas misérias. nunca lhes chegou lenitivo da parte do Poder

(...).

Quanto aos poderes da terra, quanto a Governo. este estava muito longe para se lembrar deles. Dele, pois, nunca tiveram motivo de gratidão.

(....).

Os jagunços nāo podiam compreender os motivos por que era guerreado o Conselheiro. Vivendo no meio deles dezenas de anos, o enviado de Deus nunca praticara o mal. (p.253-4).

A convicção da impossibilidade de qualquer ajuda monarquista, interna ou externa, é reiterada nas descriçōes do armamento obsoleto dos jagunços e do seu espanto e inabilidade perante as armas do Exército. Todo o equipamento de artilharia aos olhos dos jagunços transforma-se em arte do demônio, e um canhăo abandonado e levado para o reduto passa por franco processo de animismo. O monarquismo da pregaçāo do Conselheiro fica em posiçāo muito secundária, quase esquecido, sem um mínimo de identificação com os ideais dos defensores da Restauração. Numa posiçāo surpreendentemente avançada a esse respeito, Arinos apresenta uma visão muito mais próxima dos estudos sociológicos atuais ${ }^{23}$ do que dos conceitos de seu tempo. Embora enquanto caracterizaçāo de líder espiritual ocorram incoerências ao longo da narrativa, o anti-republicanismo do Conselheiro deve-se mais à resistência a inovaçōes do que a princípios monárquicos, e a estrutura social atribuída a Belo Monte é antes a das sociedades tradicionais, no modelo medieval, do que uma sociedade estruturada a partir de doutrinas comunistas. A con-

$$
{ }^{23} \text { QUEIROZ, M.I.P., 1977, p. 225-41. }
$$


cepçāo do tempo no início da narrativa é muito próxima à concepçāo primitiva de circularidade, marcada pelas comemoraçōes religiosas. É a partir do princípio da guerra que o registro cronológico passa a predominar, verdadeira entrada na História, como quer Mircea ELIADE. ${ }^{24}$ Tanto que os seguidores do Conselheiro, o "taumaturgo", o "Apóstolo de outras eras", são templários, sacerdotes, paladinos, guerreiros. . . embora cafuzos, mulatos, fulas, caboclos, crioulos retintos ou mesmo brancos. A qualificação racial e a social caminham lado a lado. Ser jagunço é uma condiçāo social que independe da cor do indivíduo, mas que não a anula. O narrador procura conservar intocadas as crenças como o fatalismo, o agouro, as superstições, numa atitude que pode ser considerada uma revivescência romântica, mas pode também de outro ângulo, ser vista como prenunciadora do século $\mathrm{XX}$. O que seguramente não parece é o comportamento de um contemporâneo do positivismo.

A figura que apresenta maior ambigüidade, fugindo ao dualismo entre personagem ficcional e de personagem histórica, é a do Conselheiro. O narrador preserva a visão dos seguidores, embora não deixe de denominá-los fanáticos. Há contradiçōes que denunciam o improviso da publicação em folhetim, mas não há dúvidas e nem explicações para seu poder adivinhatório e nem seu desaparecimento recebe justificativas racionais. O corpo desapareceu, desenterrado pelos soldados ou levado pelos próprios pés? Os sobreviventes não têm resposta, e nem o leitor. É a força de seu olhar, mais do que as palavras, que persiste na memória da leitura, emprestando-lhe uma aura mágica.

O espaço deixado com o desaparecimento do Conselheiro é preenchido por uma versão feminina do guia, do pastor do rebanho. Tia Joana, na Parte I na secundaríssima posição de mãe severa que fica só e desesperada com a morte da filha, na Parte II em princípio passa à posição de um dos protótipos dos seguidores do Conselheiro, os deserdados da sorte, a quem nada resta no mundo dos homens exceto a fé, para no desfecho sofrer a tentativa de uma transformaçāo mítica, alçada à posição de matriarca a quem compete proteger a tribo, os sobreviventes transmutados em seus filhos. É sob seu olhar que se desenrola o epiśdio derradeiro, com um tom de modernidade pela abertura da imagem biblica e pela concisão do parágrafo final, apesar da sintaxe e da adjetivação dos anteriores: "E a tribo marchou para o deserto." (p.383). Em apenas mais uma passagem do texto encontra-se construção tão despida e com tal força expressiva. Quando do interrogatório da jagunça prisioneira, o bloco é

${ }^{24}$ ELIADE, M., 1981. Capítulos 2 e 3, p.63-150. 
fechado por um magistral: "Foi degolada a jagunça." (p.352). Em Os Sertöes o registro tem a concisāo sacrificada para ganhar em ironia: "Aquela mulher, aquele demônio de anágua, aquela bruxa agourentando a vitória próxima - foi degolada. ." $25 \mathrm{E}$ na Caderneta de Campo Euclides da CUNHA relata o mesmo episódio do interrogatório sem qualquer referência à degola, detendo-se em observaçöes sobre o sistema lingüistico. ${ }^{26}$

Esta é das raras passagens em que Arinos refere-se à degola, oportunidades em que a atrocidade da prática é atenuada por ser apresentada como situaçāo enfrentada com absoluta serenidade, sem exploração de seu possivel rendimento trágico. Este é buscado em situaçōes que têm muito mais de patético, atingindo resultados antes piegas, sobretudo quando exploram a participação de crianças. É a menina que cai no tacho fervente, os pequenos desorientados no tiroteio, o grupo de mutilados da rendição, a criança que tenta introduzir um pedaço de biscoito na boca do cadáver da māe e tantas outras cenas, em que não se poupam os diminutivos e nem mesmo a reprodução gráfica da fala infantil. Arinos tem uma espécie de pudor no registro do horrivel que tanto colabora para a grandeza épica do texto euclidiano, característica já. apontada pela crítica. ${ }^{27}$ Ele desvia - olhar para o miúdo, apresentando no detalhe o que considera exemplar do conjunto. Por exemplo, nos momentos mais dramáticos das grandes batalhas, sua câmara se afasta do todo e se detém em close na cena de dois lutadores que saíram do centro e trocam golpes físicos e agressōes verbais.

A linguagem é um dos aspectos mais frágeis do texto. A voz do narrador é contaminada pelo modo de expressāo das personagens, mas não há o abandono do padrão da língua culta e da grandiloqüência. O resultado é a convivência, aparentemente no mesmo nível, de construçōes como "Caia-lhes do alto a luz sidérea em fios tênues, como lágrimas de ouro choradas pelos astros sobre o vasto e cinéreo sepulcro dos guerreiros de Belo Monte" (p.377) ao lado de expressōes do tipo: "Essa gente navegava ainda livremente por aquele mundão de meu Deus." (p.244). As comparações mitológicas e clássicas são constantes, bem como as evocaçōes bíblicas, sobretudo do Velho Testamento. Muita tinta deveria ser gasta para surgir Guimarāes Rosa. As colagens, sobretudo de trechos de cantigas, religiosas ou leigas, são numerosas, mas numa atitude que Paul ZUM-

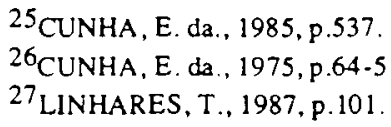


THOR identifica como de preservação de objeto museológico. ${ }^{28}$

Apesar da expressāo artificial, Arinos é homem de seu tempo, sentindo e traduzindo a tensão entre civilização e barbárie, a segunda ainda com um halo de idealização, desde que nāo tome aspectos violentos. Mas a contradição fica latente. No mesmo trecho em que se compara as "guerras feudais do sertão da Bahia" às vendettas que "só terminam pela destruição completa de uma das famílias inimigas", afirma-se que "apesar da ausência de autoridade e de força, há menos crimes (nos' sertōes brasileiros) do que numa só das nossas grandes cidades" (p.209). Ou ainda, enquanto ao longo do texto encarece a importância da ação civilizadora exercida pelo Conselheiro, como alfabetização, hábitos higiênicos, ṇormas morais, padrōes de comportamento social, afirma: "E naquele povo todo reinava a abastança, filha do trabalho. Eles não conheciam o luxo, nem o que se chama erroneamente "conforto", aí pelas cidades grandes" (p.244). A visão está mais identificada ao Euclides cauteloso de 1902 do que ao Euclides seguro de 1897 , embora sem a consciência do engenheiro-escritor.

É inócuo conjecturar sobre qual seria a sorte do romance de Afonso Arinos se não existisse o livro de Euclides da Cunha, mas a crítica exclusivamente em termos comparativos nada acrescenta ao segundo e é demolidora para o primeiro. Talvez se preste serviço mais relevante à cultura brasileira abordando-se Os Jagunços como mais um dos textos que proliferaram numa época em que os escritores tiveram presença tão marcada, seja como "polígrafos da imprensa", autênticos representantes da Belle Époque, seja como ratés, "boêmios" ou "escritores-cidadãos" para empregar a clivagem proposta por Nicolau SEVCENKO, ${ }^{29}$ que inscreve Afonso Arinos neste último grupo, cujo corifeu é Euclides da Cunha. Como é inevitável em rotulações, o efeito é simplificador. Arinos e Euclides têm pontos em comum, mas as divergências também são muito grandes e, tanto na série literária como na histórica, é preciso preservar as idiossincrasias das posturas. Neste sentido o romance merece leitura mais atenta. Embora a tiragem em volume tenha sido inexpressiva, houve antes a publicação em folhetim, o que leva a crer que tenha sido lido, ainda que não se tenha consultado material que permita inferir sobre sua repercussão. Sem sucesso mais expressivo, deve ter cumprido as funçōes do folhetim. Afonso Arinos era nome conhecido no mundo das letras e os recursos narrativos de que se serve eram correntes na produção corriqueira do fim do século.

${ }^{28}$ ZUMTHOR, P., 1983,p. 23.

${ }^{29}$ SEVCENKO, N., 1989, p.79-129. 
Quanto à vertente histórica, permaneceu fiel ao antigo regime, "mais talvez por espírito de tradiçāo e de oposição, que por conviç̧ão política", 30 na opiniāo de um biógrafo, "prova de originalidade do seu espírito e da firmeza das suas opiniōes" 31 na conclusāo de outro. Ora, num momento em que a maioria dos antigos partidários do Imperador merecia o rótulo de adesista, nāo são fartos os registros da agonizante voz monárquica. Desta perspectiva, o livro deixa seu caráter de produção individual para tomar o de expressão de uma classe. Vale resgatá-lo, ainda que só para trazer mais uma achega à tese da inviabilidade de restaurar o velho regime quando a "República era uma fatalidade para o Brasil." 32

Se para a história política interessa o registro do ponto de vista de um monarquista e para a história da ficçāo interessa o exemplar da norma literária, o modo de expressāo de uma ideologia constitui o encontro de interesses da história e ficçāo.

\section{RESUMO}

Euclides da Cunha imortalizou o episódio de Canudos em sua magistral obra Os Sertōes, publicada em 1902. Mas os acontecimentos ocorridos no interior da Bahia em 1896-97, já tinham merecido representaçāo literária. O monarquista Afonso Arinos percebera o potencial dramático dos fatos e, ainda em fins de 1897, publica. em folhetins diários do Comércio de São Paulo, a "novela sertaneja" Os Jagunços, que aparece em livro no ano seguinte. $O$ presente estudo busca apreender a dimensāo histórica e estética de tal téro.

\section{REFERÊNCIAS BIBLIOGRÁFICAS}

1 ARINOS, Afonso. Obra Completa. Rio de Janeiro: Instituto Nacional do Livro, 1969.

30 LIMA, A.A., 1966, p.547.

31 ARINOS, A., 1969, p. 18.

32 IGLÉSIAS, F., 1989, p.31 
2 CUNHA, Euclides da. Os Sertōes. Sāo Paulo : Brasiliense, 1985.

3 Caderneta de campo. São Paulo : Cult rix; Brasília: INL,

4 COUTINHO, Afrânio, (org.). A Literatura no Brasil. 3.ed. Rio de Janeiro : José Olympio; Niterói: UFF, 1986. v.4.

5 ELIADE, Mircea. O Mito do eterno retorno. Lisboa : Ediçōes 70, 1981.

6 FAORO, Raymundo. Os Donos do poder. 7.ed. Rio de Janeiro: Globo, 1987. v.2.

7 GALVĀO, Walnice Nogueira. (org.). No calor da hora. A guerra de Canudos nos jornais. São Paulo : Ática; 1974.

8 Saco de gatos. São Paulo : Duas Cidades, 1976.

9 IGLÉSIAS, Francisco. República, 1889-1989. Tempo Brasileiro. n.99, p. $31-42$, out $/$ dez. 1989.

10 LIMA, Alceu Amoroso. Estudos literários. Rio de Janeiro: Aguilar, 1966. v.1.

11 LINHARES, Temístocles. História crítica do romance brasileiro. (1728-1981). Belo Horizonte : Itatiaia; São Paulo: EDUSP, 1987. v.2.

12 LLOSA, Mário Vargas. A Guerra do fim do mundo. Rio de Janeiro: Francisco Alves, 1981.

13 MARTINS, Wilson. História da inteligência brasileira. São Paulo : Cultrix ; EDUSP, 1977-78. v.5.

14 QUEIROZ, Maria Isaura Pereira de. O Messianismo no Brasil e no mundo. 2.ed. São Paulo: Alfa-Omega, 1977.

15 RIBEIRO, João Ubaldo. Viva o povo brasileiro. Rio de Janeiro : Nova Fronteira, 1984.

16 RIEDEL, Dirce Cortes (org.). Narrativa: ficção e história. Rio de Janeiro : Imago, 1988.

17 SEVCENKO, Nicolau. Literatura como missão. 3.ed. São Paulo: Brasiliense, 1989.

18 SKIDMORE, Thomas E. Preto no branco: raça e nacionalidade no pensamento brasileiro. 2.ed. Rio de Janeiro : [s.n.], 1989.

19 SUSSEKIND, Flora. Literatura e vida literária. Rio de Janeiro : Zahar, 1985. 
20 WATT, Ian. A Ascensāo do romance. Sảo Paulo : Cia das Letras, 1990

21 WHITE, H. Tropics of discourse. Baltimore : Johns Hopkins University, 1985.

22 ZUMTHOR, Paul. Introduction à la poésie orale. Paris : Seuil, 1983. 